\title{
Development of hydrogen-selective triphenylmethoxysilane-derived silica membranes with tailored pore size by chemical vapor deposition
}

\author{
Xiao-Liang Zhang a, b, Hidetaka Yamada c, Takashi Saito c, Teruhiko Kai c, Kazuya Murakami ${ }^{\text {d, }}$

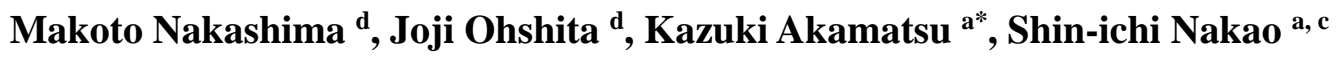

a. Department of Environmental Chemistry and Chemical Engineering, School of Advanced Engineering, Kogakuin University, 2665-1 Nakano-machi, Hachioji, Tokyo 192-0015, Japan

b. College of Chemistry and Chemical Engineering, Jiangxi Normal University, 99 Ziyang Ave, Nanchang 330022, P.R. China

c. Research Institute of Innovative Technology for the Earth, 9-2 Kizugawadai, Kizugawa, Kyoto 619-0292, Japan

d. Department of Applied Chemistry, Graduate School of Engineering, Hiroshima University,

Higashi-Hiroshima 739-8527, Japan

* Corresponding author. Tel: +81-42-628-4584; Fax: +81-42-628-4542.

E-mail: akamatsu@,cc.kogakuin.ac.jp

(C) 2015. This manuscript version is made available under the Elsevier user license http://www.elsevier.com/open-access/userlicense/1.0/ 


\section{Abstract}

Amorphous silica membranes were developed, based on an in silico molecular design, to exhibit excellent hydrogen-selective performance for separating hydrogen from mixtures containing larger organic molecules, such as methylcyclohexane and toluene. Triphenylmethoxysilane (TPMS) was synthesized and used as a novel precursor to prepare membranes by the counter-diffusion chemical vapor deposition method. Under the optimized bubbler temperature and counter-diffusion chemical vapor deposition reaction time, the fresh membranes showed high reproducibility and high hydrogen permeance in the order of $10^{-6} \mathrm{~mol} \mathrm{~m}^{-2} \mathrm{~s}^{-1} \mathrm{~Pa}^{-1}$ and high $\mathrm{H}_{2} / \mathrm{SF}_{6}$ ideal selectivity of over 12000 at $573 \mathrm{~K}$. Moreover, the TPMS-derived membrane exhibited good stability after hydrogen regeneration, even after placement in a dehumidifier cabinet at room temperature for 90 days. Single gas permeation performance and normalized Knudsen-based permeance evaluation showed that the TPMS-derived membrane (three phenyl groups on the precursor) had a pore size of 0.486 $\mathrm{nm}$, and exhibited looser structures with larger pore size than those of a diphenyldimethoxysilane (DPDMS)-derived membrane (two phenyl groups on the precursor). These results suggest that the pore size of silica membranes can be tailored with various structured silica precursors containing phenyl groups.

Keywords: Silica membrane; Triphenylmethoxysilane; Chemical vapor deposition; Quantum chemical calculation; Pore size control; 


\section{Introduction}

Hydrogen-selective membranes have gained considerable attention as membrane materials with potential uses in a broad range of applications, from large-scale hydrogen production for power generation with $\mathrm{CO}_{2}$ capture to small-scale integration with fuel cells [1-3]. Amorphous silica membranes, as one of the most promising hydrogen-selective membranes, may potentially be used over a large temperature range and under tough test conditions [1-21]. To date, two routes for the preparation of silica membranes, the sol-gel method $[1,4,6,8-10,16-20]$ and the chemical vapor deposition (CVD) method [3, 7, 11-15, 21], have been reported. However, the pore size of most reported silica membranes appears too small to efficiently separate hydrogen from hydrogenorganic gas mixtures (e.g., the methylcyclohexane-toluene-hydrogen mixture system in the methylcyclohexane dehydrogenation reaction). If the membrane pore size is controlled to approximately $0.5 \mathrm{~nm}$ and higher hydrogen permeance and permselectivity could be obtained, then such silica membrane would be a viable choice for systems, such as a mixture containing methylcyclohexane (kinetic diameter: $0.60 \mathrm{~nm})$ and toluene $(0.59 \mathrm{~nm})$. Therefore, it is important to develop a microporous membrane-structure controlled method, in particular, a method to tailor and enlarge the pores of the silica membranes.

There have been reports on the tailoring of the pore size of silica membranes by using the chemical structures of silica precursors via both the sol-gel route and CVD method. The precursors are various structured alkoxides: bridged alkoxides with $\equiv \mathrm{Si}-\mathrm{R}-\mathrm{Si} \equiv$ structure (e.g., bis(triethoxysilyl) ethane) $[19,20]$, disiloxane alkoxides with $\equiv \mathrm{Si}-\mathrm{O}-\mathrm{Si} \equiv$ structure (e.g., hexamethyldisiloxane, hexaethoxy disiloxane, tetraethoxydimethyl disiloxane) $[16,17,21]$, and silanes consisting of organic functional groups (methyl, propyl, hexyl, phenyl), which are directly 
attached to a single silicon atom $[8,11,12,22,23]$. For example, in our previous work, three series of silica membranes were prepared by the CVD method using tetramethoxysilane (TMOS), phenyltrimethoxysilane (PTMS), and diphenyldimethoxysilane (DPDMS, also called dimethoxydiphenylsilane (DMDPS) in the references $[12,14,15])$ as the silica precursors (the chemical structures of the precursors are provided in Figure 1) [12]. We found that membrane performance was successfully controlled by regulating the number of phenyl groups on the precursor. The order of gas permeance and the membrane pore size increased among the series in the same order, DPDMS $>$ PTMS $>$ TMOS. The DPDMS-derived membranes had larger pores of approximately $0.40 \mathrm{~nm}$, looser structures, and a wider pore distribution than the other two precursors [12]. The DPDMS-derived membrane showed excellent hydrogen permeance of over $10^{-6} \mathrm{~mol} \mathrm{~m}^{-2} \mathrm{~s}^{-1} \mathrm{~Pa}^{-1}$ and high $\mathrm{H}_{2} / \mathrm{SF}_{6}$ ideal selectivity of over 6800 at $573 \mathrm{~K}$. To explain the relation between the structure of the precursors and the membrane pore size, we previously focused on the bond dissociation enthalpies of the precursors. We hypothesized that the precursors formed silanone structures as important intermediates during CVD, and that these structures greatly affected the pore structures. The study indicated that the DPDMS-derived membrane was mainly prepared through the methoxyphenylsilanone intermediate, whereas the PTMS-derived and the TMOS-derived membranes were mainly prepared through the dimethoxysilanone intermediate. We proposed that the presence of phenyl groups in the intermediate has a large effect on the enlargement of the pore size [12].

Therefore, in this present study, we design and synthesize a new silica precursor, triphenylmethoxysilane (TPMS, shown in Figure 1). Quantum chemical calculations indicate that the membrane prepared with this new precursor would have larger pores than the DPDMS-derived 
membrane. However, TPMS is solid at room temperature and, because almost all the previous reports on silica membranes via CVD employ precursors in the liquid state, it would not be easy to prepare silica membranes via CVD with TPMS. Although it is a challenge to prepare silica membranes using TPMS, such membranes will have a high hydrogen permeation performance owing to the larger pore size of approximately $0.5 \mathrm{~nm}$. We first investigate the preparation parameters, such as bubbler temperature and CVD reaction time on gas permeation performance. We then present gas permeation properties, pore size evaluation and stability of the as-synthesized TPMS-derived silica membranes in this work.<smiles>CO[Si](C)(OC)OC</smiles>

Tetramethoxysilane

(TMOS)

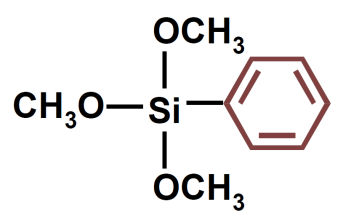

Phenyltrimethoxysilane

(PTMS)

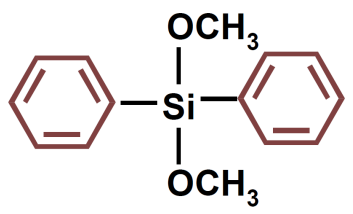

Diphenyldimethoxysilane (DPDMS)

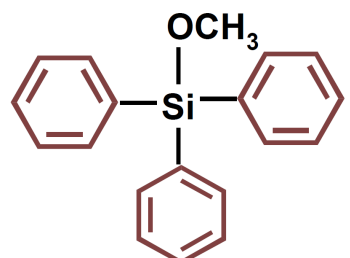

Triphenylmethoxysilane

(TPMS)

Fig. 1. Chemical structures of tetramethoxysilane (TMOS), phenyltrimethoxysilane (PTMS), diphenyldimethoxysilane (DPDMS), and triphenylmethoxysilane (TPMS).

\section{Experimental}

\subsection{Quantum chemical calculations for estimating bond energies}

The sum of electronic and thermal enthalpies in the gas phase $\left(H^{\circ}\right)$ was calculated by the geometry optimization of each compound followed by a frequency analysis for thermal and zero point energy corrections. For this calculation, we employed the density functional theory (DFT) method at the B3LYP/6-311++G(d,p) level of theory and set the most stable conformation as determined by using molecular mechanics with the Merck molecular force field (MMFF) as the 
initial geometry. Bond dissociation enthalpies or reaction enthalpies $\left(\Delta H^{\circ}\right)$ were obtained from the calculated enthalpies of the reactants $\left(H^{\circ}{ }^{\circ}\right)$ and products $\left(\Sigma H^{\circ}\right.$ pro $)$ [12]. Calculations were performed using the Gaussian09 and Spartan'14 programs.

\subsection{Preparation of TPMS monomer}

In a dry argon atmosphere, $50 \mathrm{~mL}(1.2 \mathrm{~mol})$ of methanol and $16.7 \mathrm{~mL}(120 \mathrm{mmol})$ of triethylamine were placed in a $300 \mathrm{~mL}$ two-necked flask and the flask was cooled at $273 \mathrm{~K}$. To this, $29.5 \mathrm{~g}(100 \mathrm{mmol})$ of chlorotriphenylsilane was slowly added and the mixture was stirred at this temperature for $12 \mathrm{~h}$. After the removal of excess methanol and triethylamine under reduced pressure, the residue was dissolved in $100 \mathrm{~mL}$ of diethyl ether and washed with water $(100 \mathrm{~mL} \times 3$ times). The ethereal layer was dried over anhydrous magnesium sulfate and the solvent was evaporated to provide $28.4 \mathrm{~g}$ (9.69 mmol) of TPMS as a colorless solid: m.p.: $331.1 \mathrm{~K}$; EI-MS: 290 $\left(\mathrm{M}^{+}\right) ;{ }^{1} \mathrm{H}-\mathrm{NMR}\left(400 \mathrm{MHz}\right.$, in $\left.\mathrm{CDCl}_{3}\right): \delta=3.65(\mathrm{~s}, 3 \mathrm{H}, \mathrm{MeO}), 7.36-7.48(\mathrm{~m}, 9 \mathrm{H}, m-$ and $p-\mathrm{Ph}), 7.63$ (dd, $6 \mathrm{H}, J=1.6,8.0 \mathrm{~Hz}, o-\mathrm{Ph}$ ). The NMR data, provided in the Supporting Information, agree with the data reported in the literature [24].

\subsection{Preparation and performance of TPMS-derived silica membranes}

Silica membranes were prepared by the counter-diffusion CVD method using oxygen and TPMS as the silica precursor on the modified ceramic substrates. A porous $\alpha-\mathrm{Al}_{2} \mathrm{O}_{3}$ symmetrical capillary with pore size of $150 \mathrm{~nm}$ (O.D. $6 \mathrm{~mm}$; thickness $1.1 \mathrm{~mm}$; supplied from Noritake Co. Ltd, Nagoya, Japan) was used as the substrate. As described in our previous work [12], the support was modified with a boehmite sol by a sol-gel procedure. After the dip-coating, drying, calcination processes were repeated three times, the pore size of the modified $\gamma-\mathrm{Al}_{2} \mathrm{O}_{3} / \alpha-\mathrm{Al}_{2} \mathrm{O}_{3}$ support was found to be approximately $4 \mathrm{~nm}$ by permporometry measurements. 
Figure 2 provides a schematic diagram of the CVD apparatus used for preparation of the silica membrane. The bubbler temperature of the silica precursor was kept constant in the range from 463 $\mathrm{K}$ to $528 \mathrm{~K}$ during the preparation of the silica membranes. The saturated vapor of TPMS was supplied with $200 \mathrm{~mL} \mathrm{~min}^{-1}$ of $\mathrm{N}_{2}$ as the carrier gas from the outside of the modified support, while $200 \mathrm{~mL} \mathrm{~min}^{-1}$ of $\mathrm{O}_{2}$ was supplied from the inside of the support. The CVD temperature was $873 \mathrm{~K}$, and the reaction time ranged from 60 to $90 \mathrm{~min}$. After the CVD procedure, the TPMS-derived silica layer was formed in the $\gamma-\mathrm{Al}_{2} \mathrm{O}_{3}$ pores and on the surface of the $\gamma-\mathrm{Al}_{2} \mathrm{O}_{3}$ layer.

Gas permeation performances through the as-synthesized silica membrane were measured using a single-component gas in temperatures ranging from 573 to $373 \mathrm{~K}$. As shown in Figure 2, the permeances of $\mathrm{H}_{2}, \mathrm{O}_{2}$, and $\mathrm{N}_{2}$ gas were measured by a film flow meter (SF, Horiba Ltd., Kyoto, Japan), while those of $\mathrm{CF}_{4}$ and $\mathrm{SF}_{6}$ were determined with the pressure difference method [12]. The surface and cross-section of the silica membrane were observed using FE-SEM (Hitachi, S-4800).

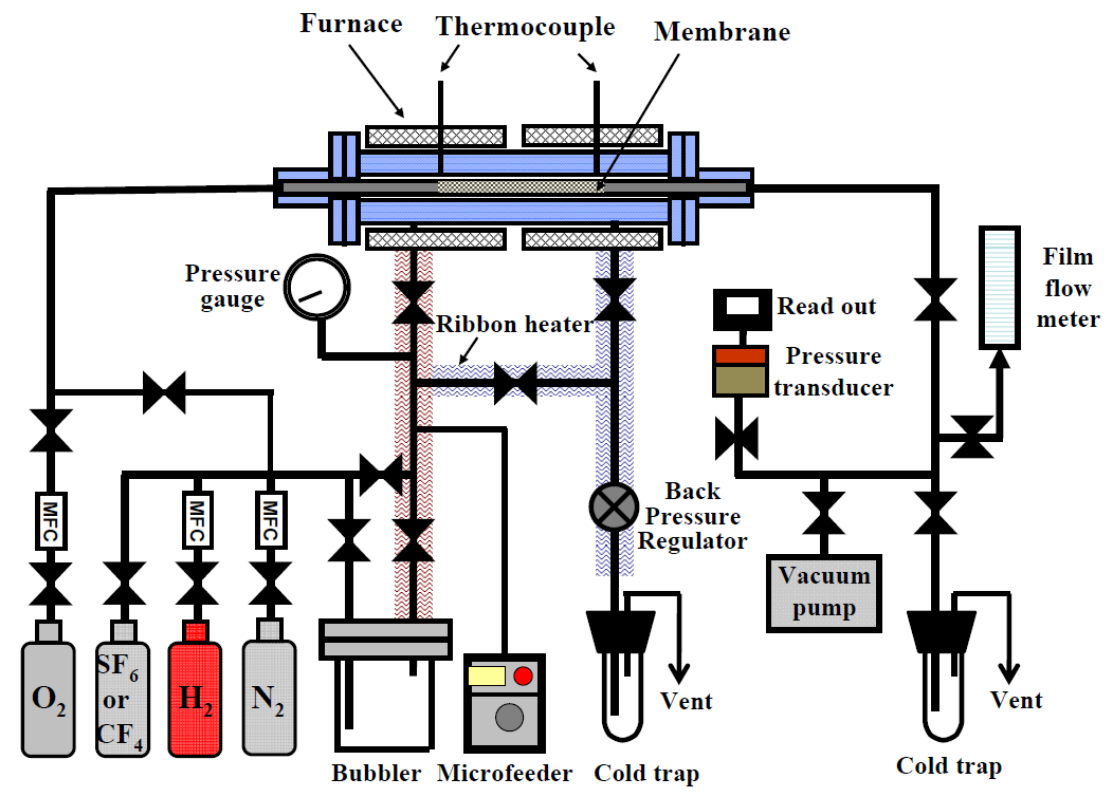

Fig. 2. Schematic diagram of experimental apparatus for preparation and gas permeation measurements of silica membranes. 


\section{Results and discussion}

\subsection{Prediction of intermediate based on DFT calculations}

Table 1 provides the bond dissociation enthalpies calculated at the B3LYP/6-311++G(d,p) level of theory. The calculated results suggest that the $\mathrm{SiO}-\mathrm{CH}_{3}$ bond is relatively weak when compared with the other bonds. Therefore, this bond will be the first to be broken for each precursor monomer in the CVD process. PTMS and DPDMS contain three and two $\mathrm{SiO}-\mathrm{CH}_{3}$ bonds, respectively, hence, a consecutive $\mathrm{SiO}-\mathrm{CH}_{3}$ bond breaking may occur to a certain extent. However, the most plausible pathway is the $\mathrm{SiO}-\mathrm{CH}_{3}$ bond breaking followed by $\mathrm{Si}-\mathrm{C}_{6} \mathrm{H}_{5}$ bond dissociation, in which the formation of a $\mathrm{Si}=\mathrm{O}$ double bond stabilizes the dissociation product.

$$
\cdot \mathrm{OSi}\left(\mathrm{OCH}_{3}\right)_{3-\mathrm{n}}\left(\mathrm{C}_{6} \mathrm{H}_{5}\right)_{\mathrm{n}} \rightarrow \mathrm{O}=\mathrm{Si}\left(\mathrm{OCH}_{3}\right)_{3-\mathrm{n}}\left(\mathrm{C}_{6} \mathrm{H}_{5}\right)_{\mathrm{n}-1}+\cdot \mathrm{C}_{6} \mathrm{H}_{5}
$$

The calculated enthalpies of reaction (1) are $131 \mathrm{~kJ} / \mathrm{mol}$ and $110 \mathrm{~kJ} / \mathrm{mol}$ for PTMS $(\mathrm{n}=1)$ and DPDMS $(n=2)$, respectively. These values are significantly smaller than the enthalpies of other possible bond breakings such as $\mathrm{SiO}_{-} \mathrm{CH}_{3}$ (ca. $350 \mathrm{~kJ} / \mathrm{mol}$ ). Consequently, silanone compounds, $\mathrm{O}=\mathrm{Si}\left(\mathrm{OCH}_{3}\right)_{3-\mathrm{n}}\left(\mathrm{C}_{6} \mathrm{H}_{5}\right)_{\mathrm{n}-1}$, are expected to form as transient intermediates in the CVD process. These results for PTMS and DPDMS agree with the previous study [12].

The newly designed and synthesized silica precursor, TPMS, contains only one $\mathrm{SiO}-\mathrm{CH}_{3}$ bond. For this precursor, the exclusive dissociation of the $\mathrm{Si}_{-} \mathrm{C}_{6} \mathrm{H}_{5}$ bond is expected after triphenylsilane radical formation. The enthalpy of reaction (1) was calculated to be $118 \mathrm{~kJ} / \mathrm{mol}$ for TPMS $(\mathrm{n}=3)$. Thus, a major intermediate will be diphenylsilanone in the TPMS-CVD process, as shown in Table 1. The intermediate compound for TPMS, $\mathrm{O}=\mathrm{Si}\left(\mathrm{C}_{6} \mathrm{H}_{5}\right)_{2}$, may easily undergo the subsequent oligomerization (Eq. 2) and oxidation reactions to form silica networks [12, 25].

$$
\mathrm{TPMS}+\mathrm{mO}=\mathrm{Si}\left(\mathrm{C}_{6} \mathrm{H}_{5}\right)_{2} \rightarrow \mathrm{CH}_{3} \mathrm{O}-\left[\mathrm{Si}\left(\mathrm{C}_{6} \mathrm{H}_{5}\right)_{2} \mathrm{O}\right]_{\mathrm{m}}-\mathrm{Si}\left(\mathrm{C}_{6} \mathrm{H}_{5}\right)_{3}
$$


The bulky phenyl groups in the siloxane segments will be burned off and replaced by the atomic oxygen in the presence of $\mathrm{O}_{2}$. So the silica membrane has a looser structure $[12,25]$. Based on the hypothesis that the size of the intermediate affects the membrane structure, we predict that the pore size distribution of the TPMS-derived membrane shifts toward a larger pore size than that of PTMS and DPDMS.

Table 1 Bond dissociation enthalpies calculated at the B3LYP/6-311++G(d,p) level and the predicted intermediates.

\begin{tabular}{|c|c|c|c|}
\hline Precursor & Bond & $\Delta H^{\circ}(\mathrm{kJ} / \mathrm{mol})$ & Intermediate \\
\hline \multirow[t]{3}{*}{ PTMS } & $\mathrm{SiO}-\mathrm{CH}_{3}$ & 357 & \\
\hline & $\mathrm{Si}-\mathrm{C}_{6} \mathrm{H}_{5}$ & 396 & \\
\hline & $\mathrm{Si}-\mathrm{OCH}_{3}$ & 453 & \\
\hline \multirow[t]{3}{*}{ DPDMS } & $\mathrm{SiO}-\mathrm{CH}_{3}$ & 353 & \\
\hline & $\mathrm{Si}-\mathrm{C}_{6} \mathrm{H}_{5}$ & 400 & \\
\hline & $\mathrm{Si}-\mathrm{OCH}_{3}$ & 438 & \\
\hline \multirow[t]{3}{*}{ TPMS } & $\mathrm{SiO}-\mathrm{CH}_{3}$ & 348 & \\
\hline & $\mathrm{Si}-\mathrm{C}_{6} \mathrm{H}_{5}$ & 374 & \\
\hline & $\mathrm{Si}-\mathrm{OCH}_{3}$ & 413 & \\
\hline
\end{tabular}

\subsection{The influence of bubbler temperature and CVD reaction time on gas permeation} performance through TPMS-derived silica membranes

The saturated vapor concentration of the silica precursor, which is generally controlled by the bubbler temperature, and CVD reaction time are the most important parameters for the preparation 
of amorphous silica membranes by the CVD method. Figure 3 shows the gas permeation results at $573 \mathrm{~K}$ through TPMS-derived silica membranes prepared with different bubbler temperatures for 60-90 min. There was no significant influence of bubbler temperature on the $\mathrm{H}_{2}$ and $\mathrm{N}_{2}$ permeances when the temperatures were varied from 463 to $528 \mathrm{~K}$. However, the $\mathrm{SF}_{6}$ permeance was seriously affected by bubbler temperature. Under the fixed oxygen flow of $200 \mathrm{~mL} \mathrm{~min}{ }^{-1}$ during the CVD process in this work, it is not appropriate to supply the TPMS with too large or too small vapor concentration to form a high-selectivity silica membrane under higher or lower bubbler temperatures. It means there should be an optimized bubbler temperature for preparing the membranes having higher $\mathrm{H}_{2}$ permeance and $\mathrm{H}_{2} / \mathrm{SF}_{6}$ selectivity. Therefore, as shown in Figure 3, the membrane prepared with a bubbler temperature of $478 \mathrm{~K}$ (the vapor concentration of TPMS was $\left.0.099 \mathrm{~mol} \mathrm{TPMS} / \mathrm{m}^{3} \mathrm{~N}_{2}\right)$ provided the highest $\mathrm{H}_{2}$ permeance $\left(1.2 \times 10^{-6} \mathrm{~mol} \mathrm{~m}^{-2} \mathrm{~s}^{-1} \mathrm{~Pa}^{-1}\right)$ and lowest $\mathrm{SF}_{6}$ permeance $\left(6.9 \times 10^{-11} \mathrm{~mol} \mathrm{~m}^{-2} \mathrm{~s}^{-1} \mathrm{~Pa}^{-1}\right)$ among the silica membranes investigated. It means that this membrane displayed a satisfactory ideal selectivity of $\mathrm{H}_{2} / \mathrm{SF}_{6}$ as high as 16800 (also presented in Table 2).

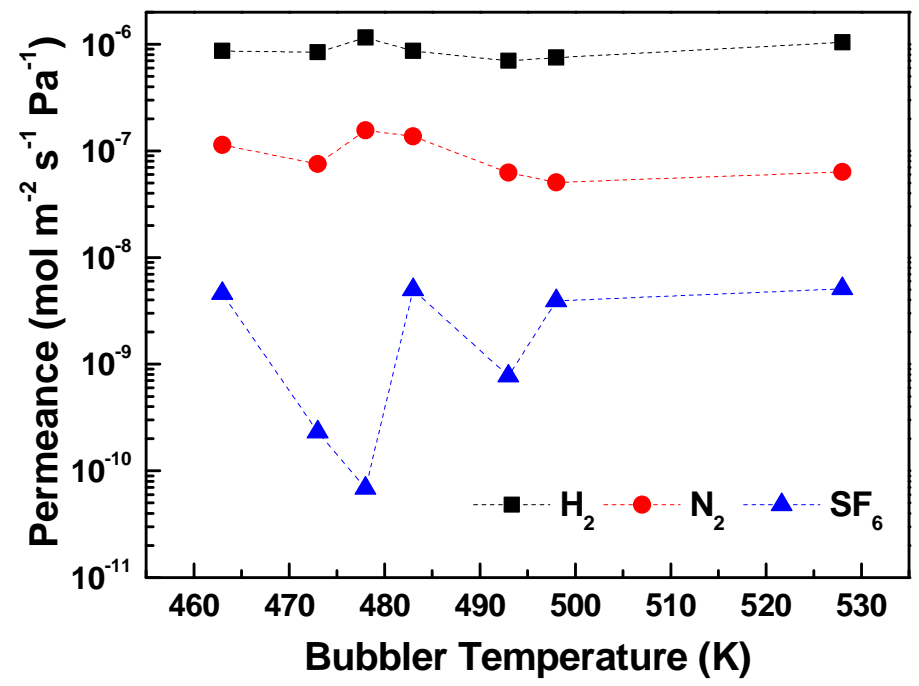

Fig. 3. Effect of bubbler temperature on gas permeation performance. 
Three series of TPMS-derived silica membranes were prepared with different CVD reaction times from 60 to 90 min when the silica bubbler temperature was set at $478 \mathrm{~K}$. Figure 4 shows the gas permeation performance of these three membranes over a temperature range from 573 to $373 \mathrm{~K}$. Commonly, the single-gas permeance of $\mathrm{H}_{2}$ and $\mathrm{SF}_{6}$ or ideal selectivity of $\mathrm{H}_{2} / \mathrm{SF}_{6}$ are evaluation criteria for excellent silica membranes. As seen in Figure 4a-c, all the gas permeances were not sensitive to a temperature variation. The order of magnitude of $\mathrm{H}_{2}$ permeance through these membranes was approximately $10^{-6} \mathrm{~mol} \mathrm{~m}^{-2} \mathrm{~s}^{-1} \mathrm{~Pa}^{-1}$ even after the CVD reaction time was increased to $90 \mathrm{~min}$. However, the order of magnitude of $\mathrm{SF}_{6}$ permeance decreased from $10^{-10}$ to $10^{-11} \mathrm{~mol} \mathrm{~m}^{-2} \mathrm{~s}^{-1} \mathrm{~Pa}^{-1}$ with an increasing CVD reaction time. Compared with the number of pores through which only hydrogen can permeate, the number of pores through which $\mathrm{SF}_{6}$ can permeate should be lower. The trend shown in Figure 4 indicates that the small number of larger pores through which $\mathrm{SF}_{6}$ can permeate would become even smaller with a prolonged CVD time. Thus, the ideal selectivity of $\mathrm{H}_{2} / \mathrm{SF}_{6}$ increased with CVD deposited time from approximately 3000 to over 16800 for these silica membranes. Meanwhile, as shown in Figure 4d, the extended CVD reaction time has almost no influence on the hydrogen and nitrogen permeances because the kinetic diameter of the hydrogen molecule $(0.289 \mathrm{~nm})$ and nitrogen molecule $(0.364 \mathrm{~nm})$ is far smaller than the pore size of these TPMS-derived membranes. Additionally, a DPDMS-derived silica membrane was also prepared at $873 \mathrm{~K}$ for 60 min using the same modified support as a comparison membrane, which is an optimized condition for DPDMS. The preparation procedure of the DPDMS (Shin-Etsu Chemical Co., Ltd., Tokyo, Japan) membrane has been described in previous work [12-15]. As shown in Figure $4 \mathrm{~d}, \mathrm{H}_{2}$ and $\mathrm{N}_{2}$ permeances of the TPMS-derived membrane reacted for $90 \mathrm{~min}$ were higher than those of the DPDMS-derived membrane, while $\mathrm{SF}_{6}$ permeance was almost the 
same at around 6.4-6.9 $\times 10^{-11} \mathrm{~mol} \mathrm{~m} \mathrm{~m}^{-2} \mathrm{~s}^{-1}$. This suggests that the TPMS-derived membrane has much larger pores and looser structures than those of the DPDMS-derived membrane.
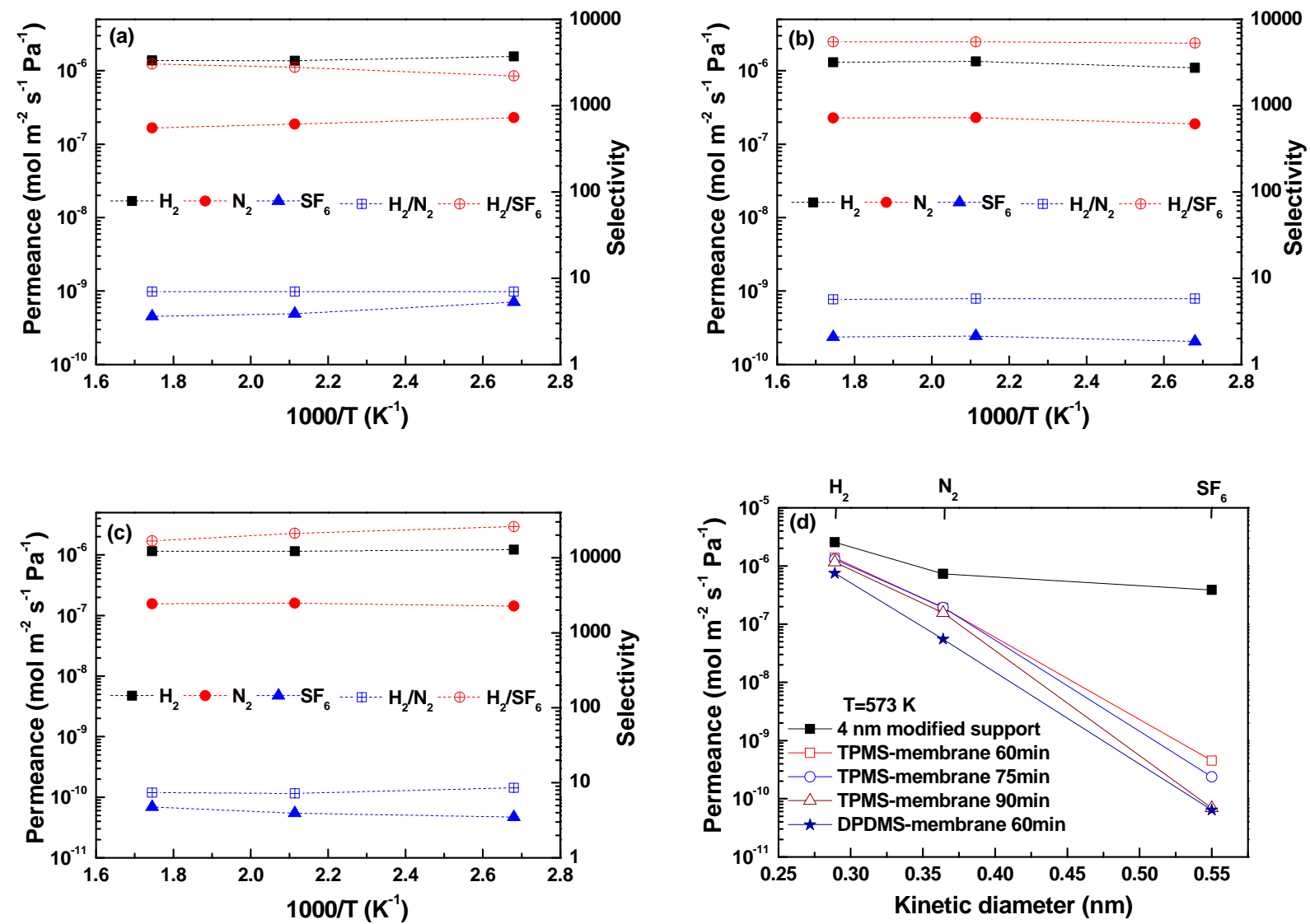

Fig. 4. Gas permeation performance through TPMS-derived silica membranes prepared with different CVD reaction times: (a) $60 \mathrm{~min}$; (b) $75 \mathrm{~min}$; (c) $90 \mathrm{~min}$; and (d) comparison with DPDMS-derived silica membranes. 


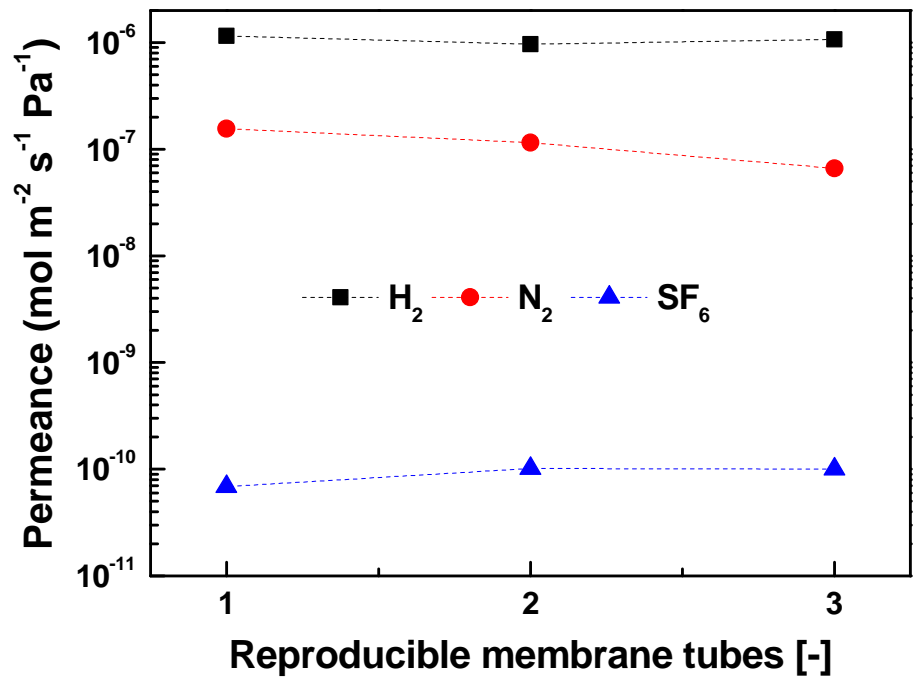

Fig. 5. The reproducibility of TPMS-derived silica membranes.
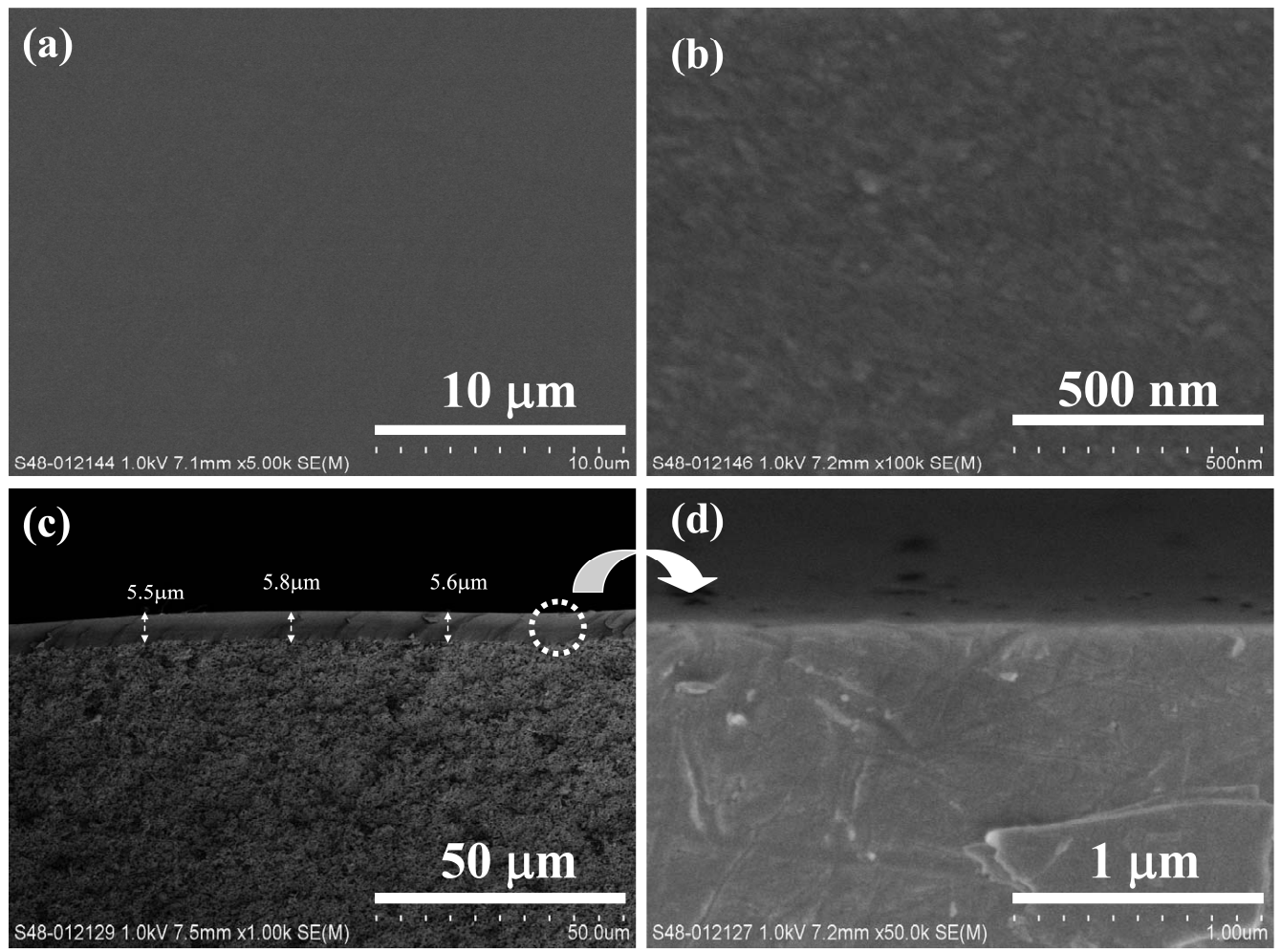

Fig. 6. SEM images of TPMS-derived silica membrane on the modified support: surface (a, b) and cross sections $(c, d)$. 
The high reproducibility of permselective membranes with high permeation properties is an important aspect for potential applications. Therefore, the reproducibility of the TPMS-derived membranes was investigated in this work. Three series of silica membranes were prepared under the same optimized conditions, that is, a bubbler temperature of $478 \mathrm{~K}$ and CVD reaction time of 90 min. As shown in Figure 5, these membranes exhibited high hydrogen permeance and $\mathrm{H}_{2} / \mathrm{SF}_{6}$ ideal selectivity at $573 \mathrm{~K}$. The average values of $\mathrm{H}_{2}, \mathrm{~N}_{2}$, and $\mathrm{SF}_{6}$ permeance were $(1.07 \pm 0.07) \times 10^{-6}$ mol m${ }^{-2} \mathrm{~s}^{-1} \mathrm{~Pa}^{-1},(1.13 \pm 0.37) \times 10^{-7} \mathrm{~mol} \mathrm{~m}^{-2} \mathrm{~s}^{-1} \mathrm{~Pa}^{-1}$, and $(9.02 \pm 1.51) \times 10^{-11} \mathrm{~mol} \mathrm{~m}^{-2} \mathrm{~s}^{-1} \mathrm{~Pa}^{-1}$, respectively, corresponding to an average $\mathrm{H}_{2} / \mathrm{SF}_{6}$ ideal selectivity of over 12000 . These results exhibit the high reproducibility of the TPMS-derived membranes. As seen in Figure 6, the continuous compact $\gamma-\mathrm{Al}_{2} \mathrm{O}_{3}$ layer of around $5.5 \mu \mathrm{m}$ was uniformly formed on the support. Amorphous silica was deposited in the $\gamma-\mathrm{Al}_{2} \mathrm{O}_{3}$ pores and on the surface of the $\gamma-\mathrm{Al}_{2} \mathrm{O}_{3}$ layer, which was also reported in our previous work [12]. Although the thickness of the $\mathrm{SiO}_{2}$ layer, which determines hydrogen permeance, is not clear at this stage, such a uniform layer (see Fig. 6b and Fig. $6 \mathrm{~d}$ of high magnification images) results in the high hydrogen permeance in the order of $10^{-6} \mathrm{~mol}$ $\mathrm{m}^{-2} \mathrm{~s}^{-1} \mathrm{~Pa}^{-1}$ and ideal selectivity of $\mathrm{H}_{2} / \mathrm{SF}_{6}$ over 12000 .

\subsection{Gas permeation properties through TPMS-derived silica membranes}
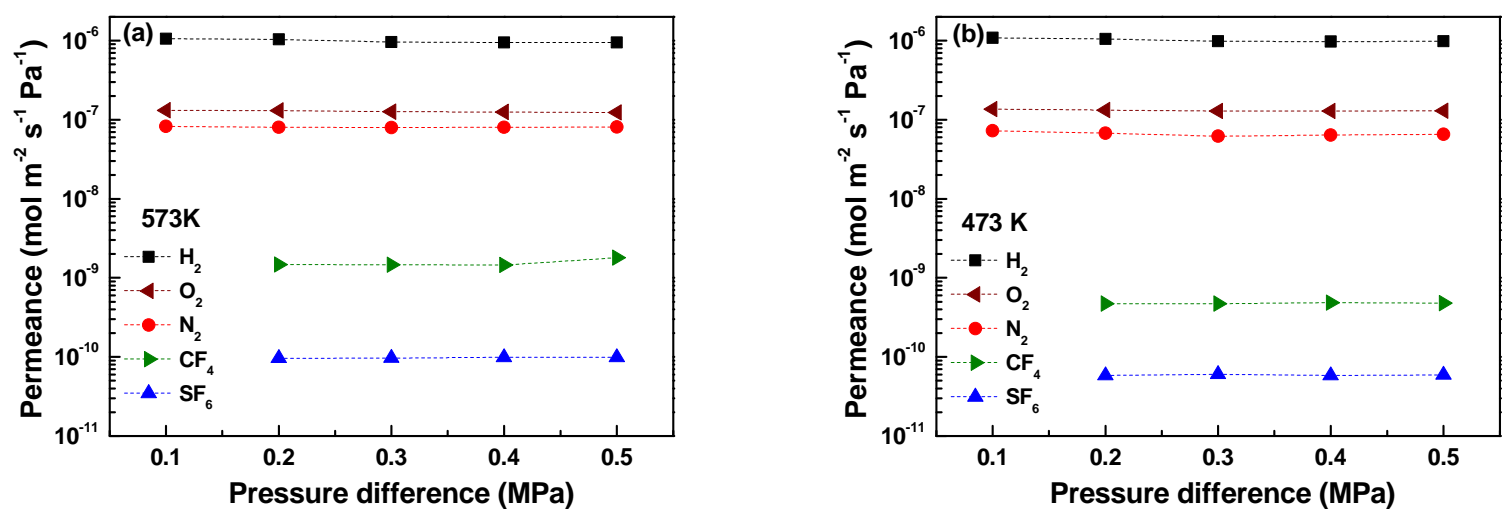

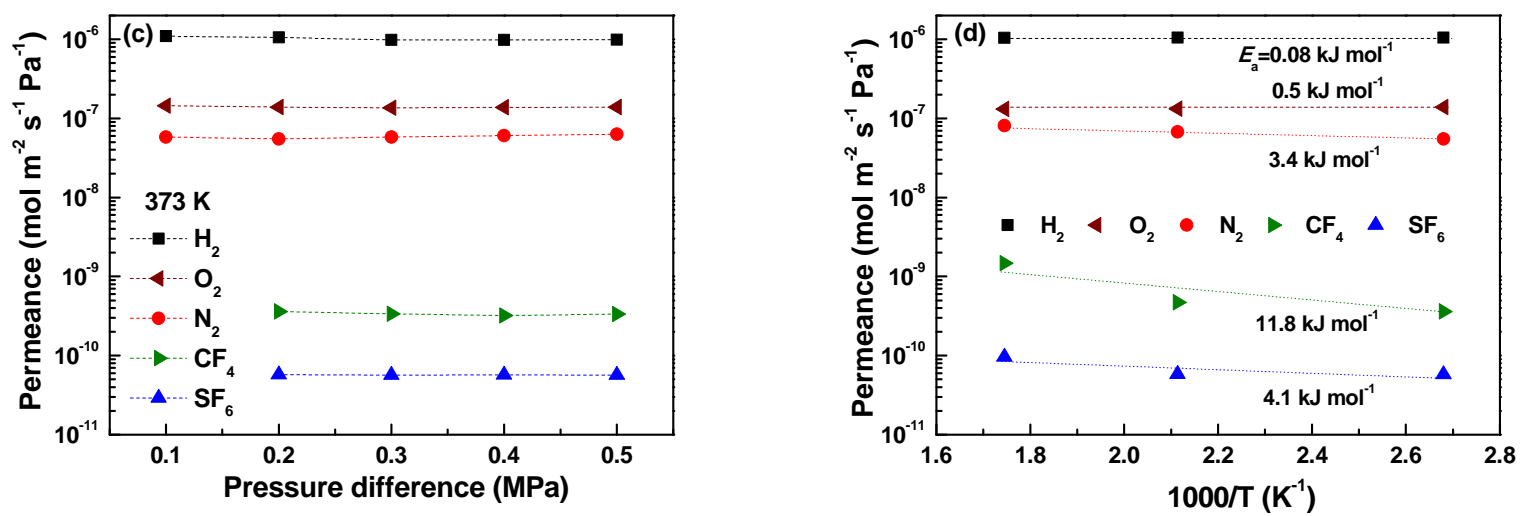

Fig. 7. Gas permeation properties of the TPMS-derived silica membrane: the pressure difference effect on gas permeation performance at (a) $573 \mathrm{~K}$; (b) $473 \mathrm{~K}$; and (c) $373 \mathrm{~K}$; and (d) Arrhenius plots of the gas permeances through the membrane at a pressure difference of $0.2 \mathrm{MPa}$.

The performances of the silica membrane prepared under the optimized conditions were investigated by determining the gas permeation properties under different temperatures from 573 to $373 \mathrm{~K}$ and pressure differences ranging from 0.1 to $0.5 \mathrm{MPa}$. As shown in Figure $7 \mathrm{a}-\mathrm{c}$, the permeances of $\mathrm{H}_{2}, \mathrm{O}_{2}, \mathrm{~N}_{2}, \mathrm{CF}_{4}$, and $\mathrm{SF}_{6}$ hardly showed any dependency on the pressure differences at the temperature region investigated in this work. Moreover, the order of magnitude of $\mathrm{H}_{2}$ permeance was approximately $10^{-6} \mathrm{~mol} \mathrm{~m}^{-2} \mathrm{~s}^{-1} \mathrm{~Pa}^{-1}$ while that of $\mathrm{SF}_{6}$ was below $10^{-10} \mathrm{~mol} \mathrm{~m}^{-2} \mathrm{~s}^{-1}$ $\mathrm{Pa}^{-1}$. This shows that this TPMS-derived membrane displays high $\mathrm{H}_{2} / \mathrm{SF}_{6}$ ideal selectivity over 10000 under the different temperatures and pressure differences.

Generally, the gas permeance through the silica membranes is activated, and increases with increasing temperatures. Thus, the activation energies $\left(E_{a}\right)$ of the gas permeation are obtained by fitting the experimental data to the Arrhenius law, using the following:

$$
Q=Q_{0} \exp \left(-E_{a} / R T\right),
$$

where $Q$ and $Q_{0}$ are the $i$ th component gas permeance and permeation coefficient, respectively. 
Figure $7 \mathrm{~d}$ shows the Arrhenius plots of all the gas permeances through the TPMS-derived membrane under the pressure difference of $0.2 \mathrm{MPa}$ according to the permeation results in Figure 7a-c. The permeances of $\mathrm{H}_{2}$ and $\mathrm{O}_{2}$ rarely showed any dependency on the permeation temperature. Their activation energies for permeation through the membrane were only 0.08 and $0.5 \mathrm{~kJ} \mathrm{~mol}^{-1}$ for $\mathrm{H}_{2}$ and $\mathrm{O}_{2}$, respectively. It should be noted that the activation energy of hydrogen through the TPMS-derived membrane is very lower than that of TMOS-, PTMS-, and DPDMS-derived membranes that were reported in our previous work, which were 19 , 11, and $0.8 \mathrm{~kJ} \mathrm{~mol}^{-1}$, respectively [12], and that of silica membranes summarized in Ref. [3] where $E_{a}$ was reported to be in the range of $2.2-25 \mathrm{~kJ} \mathrm{~mol}^{-1}$ (see the Table 2 in Ref. [3]). Only the permeance of $\mathrm{CF}_{4}$ exhibited a higher activation energy of $11.8 \mathrm{~kJ} \mathrm{~mol}^{-1}$, while that of $\mathrm{SF}_{6}$ was $4.1 \mathrm{~kJ} \mathrm{~mol}^{-1}$. This indicates that the TPMS-derived membrane has large micropores from approximately 0.47 to $0.55 \mathrm{~nm}$ estimated on the basis of the molecular kinetic diameter of $\mathrm{CF}_{4}$ and $\mathrm{SF}_{6}$. The lower activation energies indicate that the TPMS (containing three phenyl groups)-derived membrane has a looser silica network and much larger pores than the TMOS-, PTMS-, and DPDMS-derived membranes investigated in our previous work owing to the different chemical structures for these silica precursors, which greatly influence the enlargement of pore size of the silica membranes [12]. This is also consistent with the results for pore size prediction by DFT calculations in the preceding Section 3.1 and the pore size evaluation in Section 3.5 .

\subsection{Membrane regeneration}


Table 2 Gas permeation performance of the silica membrane at $573 \mathrm{~K}$ before and after membrane regeneration.

\begin{tabular}{lccccc}
\hline & $\begin{array}{c}\mathrm{H}_{2} \text { permeance } \\
\left(\mathrm{mol} \mathrm{m}^{-2} \mathrm{~s}^{-1} \mathrm{~Pa}^{-1}\right)\end{array}$ & $\begin{array}{c}\mathrm{N}_{2} \text { permeance } \\
\left(\mathrm{mol} \mathrm{m}^{-2} \mathrm{~s}^{-1} \mathrm{~Pa}^{-1}\right)\end{array}$ & $\begin{array}{c}\mathrm{SF}_{6} \text { permeance } \\
\left(\mathrm{mol} \mathrm{m}^{-2} \mathrm{~s}^{-1} \mathrm{~Pa}^{-1}\right)\end{array}$ & $\begin{array}{c}\mathrm{H}_{2} / \mathrm{N}_{2} \\
\text { ideal } \\
\text { selectivity }\end{array}$ & $\begin{array}{c}\mathrm{H}_{2} / \mathrm{SF}_{6} \\
\text { ideal } \\
\text { selectivity }\end{array}$ \\
\hline $\begin{array}{c}\text { Fresh membrane } \\
\text { Exposure at R.T. } \\
\text { for 90 days }\end{array}$ & $1.2 \times 10^{-6}$ & $1.6 \times 10^{-7}$ & $6.9 \times 10^{-11}$ & 7.5 & 16800 \\
After regeneration & $1.7 \times 10^{-9}$ & $2.7 \times 10^{-10}$ & $4.9 \times 10^{-11}$ & 13.7 & 76 \\
\hline
\end{tabular}

As shown in Table 2 and the above discussion, the fresh membrane prepared under the optimized conditions displayed high hydrogen permeance and $\mathrm{H}_{2} / \mathrm{SF}_{6}$ ideal selectivity. However, after placement in a dehumidifier cabinet (the humidity lower than $1 \% \mathrm{RH}$ ) at room temperature for 90 days, the $\mathrm{H}_{2}$ permeance of the membrane at $573 \mathrm{~K}$ drastically decreased from $1.2 \times 10^{-6}$ to $3.7 \times 10^{-9} \mathrm{~mol} \mathrm{~m}^{-2} \mathrm{~s}^{-1} \mathrm{~Pa}^{-1}$, as did the $\mathrm{N}_{2}$ permeance, from $1.6 \times 10^{-7}$ to $2.7 \times 10^{-10} \mathrm{~mol} \mathrm{~m}^{-2} \mathrm{~s}^{-1} \mathrm{~Pa}^{-1}$. $\mathrm{SF}_{6}$ permeance displayed less of a change, from $6.9 \times 10^{-11}$ to $4.9 \times 10^{-11} \mathrm{~mol} \mathrm{~m}^{-2} \mathrm{~s}^{-1} \mathrm{~Pa}^{-1}$. This may be attributed to the small amount of physically adsorbed water molecules on the membrane surface or on the inside of the pore, thus decreasing the effective pore size for gas permeation [14].

Pure hydrogen gas was fed at $300 \mathrm{~mL} \mathrm{~min}^{-1}$ from the outside of the tubular membrane keeping the pressure difference at $0.2 \mathrm{MPa}$ in order to evaluate membrane regeneration at $573 \mathrm{~K}$. After regeneration for about $12 \mathrm{~h}$, the permeance of $\mathrm{H}_{2}$ and $\mathrm{SF}_{6}$ was recovered, and the recovery of $\mathrm{N}_{2}$ permeance was not as significant, which is similar to a previous report [14]. Good stability and high hydrogen permeation performance was observed for this membrane after regeneration as shown in Table 2. Based on the above results, the TPMS-derived membrane demonstrated good stability even after being placed in the dehumidifier cabinet at room temperature for as long as three months. 


\subsection{Pore size evaluation of the TPMS-derived silica membrane}

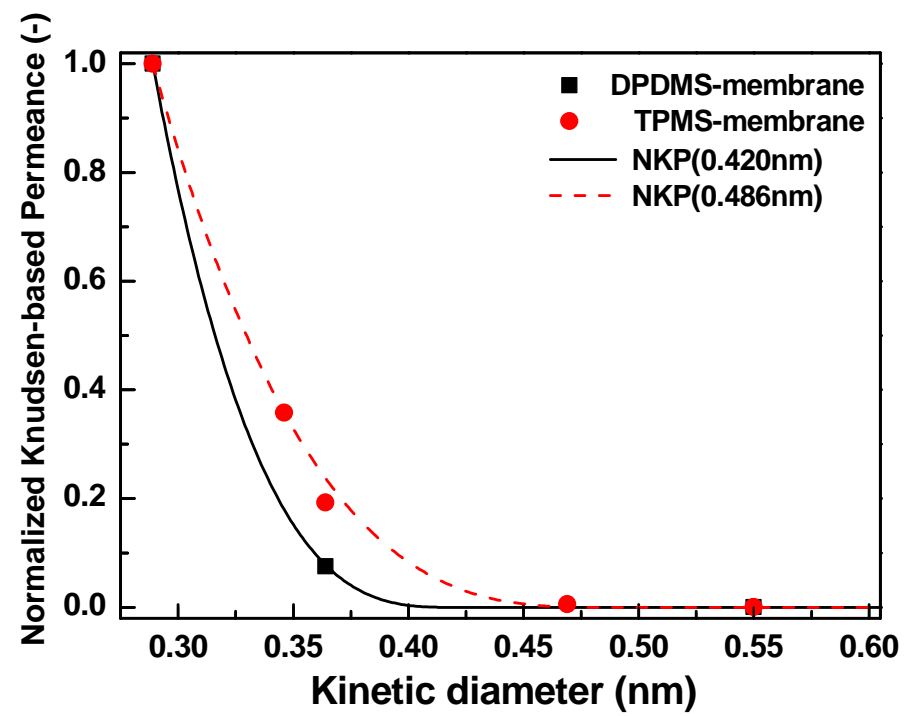

Fig. 8. Pore size evaluation of the TPMS-derived silica membrane compared with the DPDMS-derived silica membrane.

The normalized Knudsen-based permeance (NKP) method is an effective mathematic model to evaluate the pore size of microporous membranes, such as zeolite membranes and silica membranes whose pore sizes are less than $1 \mathrm{~nm}[18,19]$. As shown in Figure 4d, the permeation resistances through the modified support were not as small as those through the silica membranes overall. According to the support resistance model [26-28], we exclude the permeation resistance of the support based on the gas permeation data in Figure $4 \mathrm{~d}$ and Figure 7. The membrane layers are treated as analogous to electrical resistors in series, and the membrane resistance for gas permeation is assumed as a series process of the supports and top-layer resistance, where the permeation is the reciprocal of the resistance (Eq. 4) [26-28]:

$$
1 / Q_{\text {total }}=1 / Q_{\text {top-layer }}+1 / Q_{\text {support }}
$$

Hydrogen is the smallest molecule in this work, which is thus taken as a reference (jth component).

The NKP value is the permeance ratio of the $i$ th component $\left(\mathrm{P}_{i}\right)$ to that predicted from $\mathrm{H}_{2}$ 
permeation based on the Knudsen diffusion mechanism $\left(\mathrm{P}_{H 2}\left(\mathrm{M}_{j} / \mathrm{M}_{i}\right)^{1 / 2}\right)[18,19]$. The pore size evaluation of TPMS-derived silica membrane by the NKP method is shown in Figure 8. The NKP simulated curve was in agreement with the membrane permeation data. The pore size of TPMS-derived membrane was evaluated as approximately $0.486 \mathrm{~nm}$, which is between the kinetic diameters of $\mathrm{CF}_{4}(0.47 \mathrm{~nm})$ and $\mathrm{SF}_{6}(0.55 \mathrm{~nm})$. This also was in agreement with the discussion of the membrane activation energy provided in Section 3.3. For comparison, the DPDMS-derived membrane shown in Figure 4 indicates a pore size of around $0.420 \mathrm{~nm}$ with the NKP method (Figure 8). These results also suggest that the TPMS-derived membrane had looser structures and larger pore size than those of the DPDMS-derived membrane.

\section{Conclusions}

With the aid of quantum chemical calculations employing the DFT method at the B3LYP/6-311++G(d,p) level of theory, we designed and synthesized TPMS as a new silica precursor for preparation of the silica membrane with high permeation performance and with a larger pore size than those of PTMS- and DPDMS-derived membranes.

A uniform silica membrane was prepared by the counter-diffusion CVD method using oxygen and TPMS on the modified alumina substrates. The TPMS-derived silica membranes, which were prepared under the optimized bubbler temperature and CVD reaction time, showed excellent hydrogen permeance in the order of $10^{-6} \mathrm{~mol} \mathrm{~m}^{-2} \mathrm{~s}^{-1} \mathrm{~Pa}^{-1}$ and high ideal selectivity of $\mathrm{H}_{2} / \mathrm{SF}_{6}$ over 12000 at $573 \mathrm{~K}$. The silica membranes showed high reproducibility and good stability. High recovery of hydrogen permeation after membrane regeneration was observed even with exposure to room temperature for three months. 
The TPMS-derived membrane was successfully tuned to have a pore size of approximately $0.50 \mathrm{~nm}$ according to the NKP evaluation method. It had looser structures and larger pore size than those of the DPDMS-derived membrane. Based on the results of the DFT calculations, we demonstrated that the pore size of silica membranes can be controlled by tuning the bond energies and substituent size of the silica precursor. The large groups, such as phenyl groups, in silica precursors exert a large influence on the augmentation of the pore size of amorphous silica membranes.

In summary, the development of such TPMS-derived membranes with high hydrogen permeation performance should provide more opportunities for high-purity hydrogen production from organic chemical hydrides.

\section{Acknowledgments}

This research was supported by Council for Science, Technology and Innovation (CSTI), Cross-ministerial Strategic Innovation Promotion Program (SIP), and "energy carrier" (Funding agency: JST). We also thank Noritake Co. Ltd., Japan, for kindly supplying the $\alpha$-alumina tube.

\section{References}

[1] R.M. de Vos, H. Verweij, High-selectivity, high-flux silica membranes for gas separation, Science 279 (1998) 1710-1711.

[2] Y.F. Gu, S.T. Oyama, High molecular permeance in a poreless ceramic membrane, Adv. Mater. 19 (2007) 1636-1640.

[3] S.J. Khatib, S.T. Oyama, Silica membranes for hydrogen separation prepared by chemical vapor deposition (CVD), Sep. Purif. Technol. 111 (2013) 20-42. 
[4] H. Qi, J. Han, N.P. Xu, H.J.M. Bouwmeester, Hybrid organic-inorganic microporous membranes with high hydrothermal stability for the separation of carbon dioxide, ChemSusChem 3 (2010) 1375-1378.

[5] N. Bighane, W.J. Koros, Novel silica membranes for high temperature gas separations, J. Membr. Sci. 371 (2011) 254-262.

[6] C. Yacou, S. Smart, J.C.D. da Costa, Long term performance cobalt oxide silica membrane module for high temperature $\mathrm{H}_{2}$ separation, Energy Environ. Sci. 5 (2012) 5820-5832.

[7] H.S. Choi, C.H. Ryu, G.J. Hwang, Obtention of $\mathrm{ZrO}_{2}-\mathrm{SiO}_{2}$ hydrogen permselective membrane by chemical vapor deposition method, Chem. Eng. J. 232 (2013) 302-309.

[8] H. H. El-Feky, K. Briceno, E.O. Jardimc, J. Silvestre-Albero, T. Gumí, Novel silica membrane material for molecular sieve applications, Microporous Mesoporous Mater., 179 (2013) 22-29.

[9] B. Ballinger, J. Motuzas, S. Smart, J.C.D. da Costa, Palladium cobalt binary doping of molecular sieving silica membranes, J. Membr. Sci. 451 (2014) 185-191.

[10]T. V. Gestel, F. Hauler, M. Bram, W. A. Meulenberg, H. P. Buchkremer, Synthesis and characterization of hydrogen-selective sol-gel $\mathrm{SiO}_{2}$ membranes supported on ceramic and stainless steel supports, Sep. Purif. Technol. 121 (2014) 20-29.

[11]E. Matsuyama, A. Ikeda, M. Komatsuzaki, M. Sasaki, M. Nomura, High-temperature propylene/propane separation through silica hybrid membranes, Sep. Purif. Technol. 128 (2014) 25-30.

[12]Y. Ohta, K. Akamatsu, T. Sugawara, A. Nakao, A.Miyoshi, S.-I. Nakao, Development of pore size-controlled silica membranes for gas separation by chemical vapor deposition, J. Membr. Sci. 315 (2008) 93-99. 
[13]K. Oda, K. Akamatsu, T. Sugawara, R. Kikuchi, A. Segawa, S.-I. Nakao, Dehydrogenation of methylcyclohexane to produce high-purity hydrogen using membrane reactors with amorphous silica membranes, Ind. Eng. Chem. Res. 49 (2010) 11287-11293.

[14]T. Saito, M. Seshimo, K. Akamatsu, K.Miyajima, S.-I. Nakao, Effect of physically adsorbed water molecules on the $\mathrm{H}_{2}$-selective performance of a silica membrane prepared with dimethoxydiphenylsilane and its regeneration, J. Membr. Sci. 392-393 (2012) 95-100.

[15]M. Seshimo, K. Akamatsu, S. Furuta, S.-I. Nakao, $\mathrm{H}_{2}$ purification durability of dimethoxydiphenylsilane-derived silica membranes with $\mathrm{H}_{2}$-toluene mixtures, Ind. Eng. Chem. Res. 52 (2013)17257-17262.

[16]H.R. Lee, M. Kanezashi, Y. Shimomura, T. Yoshioka, T. Tsuru, Evaluation and fabrication of pore-size-tuned silica membranes with tetraethoxydimethyl disiloxane for gas separation, AIChE J 57 (2011) 2755-2765.

[17]H.R. Lee, T. Shibata, M. Kanezashi, T. Mizumo, J. Ohshita, T. Tsuru, Pore-size-controlled silica membranes with disiloxane alkoxides for gas separation, J. Membr. Sci. 383 (2011) $152-158$.

[18]G. Li, K. Yada, M. Kanezashi, T. Yoshioka, T. Tsuru, Methylcyclohexane dehydrogenation in catalytic membrane reactors for efficient hydrogen production, Ind. Eng. Chem. Res. 52 (2013) $13325-13332$.

[19]T. Niimi, H. Nagasawa, M. Kanezashi, T. Yoshioka, K. Ito, T. Tsuru, Preparation of BTESE-derived organosilica membranes for catalytic membrane reactors of methylcyclohexane dehydrogenation, J. Membr. Sci. 455 (2014) 375-383.

[20]J.H. Wang, G.H. Gong, M. Kanezashi, T. Yoshioka, K. Ito, T. Tsuru, Pervaporation performance 
and characterization of organosilica membranes with a tuned pore size by solid-phase $\mathrm{HCl}$ post-treatment, J. Membr. Sci. 441 (2013) 120-128

[21]H. Nagasawa, T. Minamizawa, M. Kanezashi, T. Yoshioka, T. Tsuru, High-temperature stability of PECVD-derived organosilica membranes deposited on $\mathrm{TiO}_{2}$ and $\mathrm{SiO}_{2}-\mathrm{ZrO}_{2}$ intermediate layers using HMDSO/Ar plasma, Sep. Purif. Technol. 121 (2014) 13-19.

[22]B.K. Sea, K. Kusakabe, S. Morooka, Pore size control and gas permeation kinetics of silica membranes by pyrolysis of phenyl-substituted ethoxysilanes with cross-flow through a porous support wall, J. Membr. Sci. 130 (1997) 41-52.

[23]Y.F. Gu, B. Vaezian, S.J. Khatib, S.T. Oyama, Z.X. Wang, L. Achenie, Hybrid $\mathrm{H}_{2}$-selective silica membranes prepared by chemical vapor deposition, Sep. Sci. Technol., 47 (2012) 1698-1708.

[24]R. Savela, W. Zawartka and R. Leino, Iron-catalyzed chlorination of silanes, Organometallics 31 (2012) 3199-3206.

[25]A.M. Wróbel, A.Walkiewicz-Pietrzykowska, Y. Hatanaka, S. Wickramanayaka, Y. Nakanishi, Oligomerization and polymerization steps in remote plasma chemical vapor deposition of silicon-carbon and silica films from organosilicon sources, Chem. Mater. 13 (2001) 1884-1895.

[26]R.S.A. de Lange, J.H.A. Hekkink, K. Keizer, A.J. Burggraaf, Formation and characterization of supported microporous ceramic membranes prepared by sol-gel modification techniques, J. Membr. Sci. 99 (1995) 57-75.

[27]D.L. Meixner, P.N. Dyer, Characterization of the transport properties of microporous inorganic membranes, J. Membr. Sci. 140 (1998) 81-95. 
[28]H. Li, U. Schygulla, J. Hoffmann, P. Niehoff, K. Haas-Santo, R. Dittmeyer, Experimental and modeling study of gas transport through composite ceramic membranes, Chem. Eng. Sci. 108 (2014) 94-102. 
Graphical Abstract

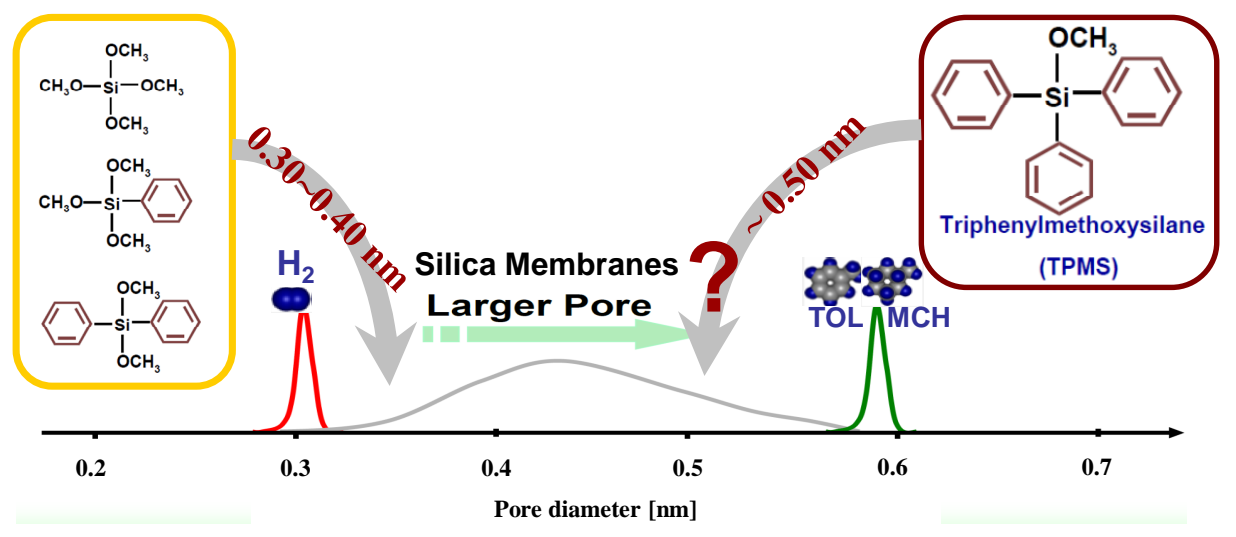

